\title{
Effects of Dietary Chitosan and Neem Leaf Meal Supplementation on Digestive Enzyme Activities and Fat Deposition in Broiler Chickens
}

\author{
D. Sirsat Shraddha ${ }^{1 *}$, P. Visha ${ }^{2}$ and K. Nanjappan ${ }^{2}$ \\ ${ }^{1}$ Department of Veterinary Physiology, Bombay Veterinary College, Mumbai, India \\ ${ }^{2}$ Department of Veterinary Physiology, Veterinary College and Research Institute, \\ Namakkal, India \\ *Corresponding author
}

\begin{tabular}{|c|c|}
\hline & A B S T R A C T \\
\hline Keywords & \multirow{4}{*}{$\begin{array}{l}\text { A study was conducted to determine the effects of dietary supplementation with } \\
\text { chitosan, neem leaf meal and their combination at different levels in broiler on fat } \\
\text { deposition and intestinal ph and digestive enzymes, amylase and lipase. Two } \\
\text { hundred forty broilers (Vencobb) were randomly assigned to eight groups with } \\
\text { three replicates of ten birds each and were fed for six weeks and slaughtered. } \\
\text { Supplementation of antibiotic, chitosan, NLM and chitosan NLM combination had } \\
\text { no influence on the activities of intestinal amylase and lipase except that the } \\
\text { chitosan supplemented groups recorded lower lipase activity than other treatment } \\
\text { groups. The birds supplemented with chitosan at } 0.025 \% \text { and } 0.05 \% \text { alone or in } \\
\text { combination with NLM at } 0.025 \% \text { chitosan and } 0.5 \% \text { neem leaf meal and } 0.05 \% \\
\text { chitosan and } 1.0 \% \text { neem leaf meal both the levels resulted in significant (p<0.05) } \\
\text { reduction in abdominal fat in comparison to all other treatment and control groups. }\end{array}$} \\
\hline $\begin{array}{l}\text { Abdominal fat, } \\
\text { broiler, } \\
\text { chitosan, } \\
\text { digestive enzymes, } \\
\text { neem leaf meal. }\end{array}$ & \\
\hline Article Info & \\
\hline $\begin{array}{l}\text { Accepted: } \\
\text { 04 April } 2017 \\
\text { Available Online: } \\
10 \text { May } 2017\end{array}$ & \\
\hline
\end{tabular}

\section{Introduction}

An emphasis on nutrition and health, mainly diet, saturated fat, cholesterol and obesity by consumers has changed the demand for food products, especially meat. Health conscious consumers associate diet with the probability of experiencing health problems or diseases. The desire of the consumers to eat healthy foods which are free from antibiotic residues and other negative attributes lead to the search for natural or organic substitutes for synthetic antibiotics which is commonly used by poultry producers today. The growth and expansion of the poultry industry is confronted by high cost of feed and drugs and their occasional shortages. However, there is the fear that the continuous subtherapeutic use of in-feed antibiotics could lead to the development of antibiotic resistant bacteria, which can be harmful to humans (Nasir and Grashorn, 2006). Thus, efforts have been made in different parts of the world to ban the inclusion of all types of antibiotic growth promoters in animal feeds.

Chitin is a cellulose-like biopolymer found in the arthropods (Austine et al., 1981). Chitosan, a deacetylated product of chitin, is produced industrially from crab and shrimp 
shell waste obtained from the sea. Chitosan derived from shell wastes has multifunctional activities such as immunopotenting, antibacterial, antifungal, antioxidant, wound healing, antiulcer and antitumor effects. It has a unique combination of properties such as biocompatibility, biodegradability, biorenewable and biofunctional activity which makes it an ideal polymer for wide range of applications including agriculture, food science, pharmaceuticals and biomedical fields (Shahidi et al., 1999; Yin et al., 2009). Additionally, chitosan enhances the digestion and absorption of nutrients when incorporated at lower levels in diets. (Gopalakannan and Venkatesan, 2006) and it has synergistic action with antibiotics and neem against many bacteria (Tin et al., 2009; Rajendran et al., 2012).

Previously, it was reported that dietary chitosan inhibited the increases in plasma triglyceride concentration and abdominal fat weight induced by the feeding of high-fat diets in laying-type chicks (Kobayashi and Itoh, 1991). Dietary chitosan also reduced plasma cholesterol concentrations (Razdan and Pettersson, 1994; Razdan et al., 1997), postprandial plasma triglyceride (Razdan and Pettersson, 1994) and ileal fat digestibility (Razdan and Pettersson, 1996) in broiler chickens. Accordingly, it was suggested that dietary chitosan may decrease the absorption of dietary fat and the deposition of fat in broiler chickens. Pancreatic lipase and amylase plays an important role in fat absorption.

Azadirachta indica, commonly known as neem, has attracted worldwide attention in recent years, owing to its wide range of medicinal properties. Neem is a tropical evergreen tree native to Indian sub-continent. Neem possesses limonoids, protolimonoids, tetranortriterpenoids, pentanortri-terpenoids, hexanortriterpenoids, and some nonterpenoid (Koul et al., 2006). Most of the plant parts such as fruits, seeds, leaves, bark, and roots contain compounds with proven antiseptic, antiviral, antipyretic, anti-inflammatory, antiulcer, and antifungal properties (Brahmachari, 2004). Neem leaves exhibit immunomodulatory, anti-inflammatory, antihyperglycaemic, antiulcer, antimalarial, antifungal, antibacterial, antiviral, antioxidant, antimutagenic and anticarcinogenic properties (Tiwari et al., 2014). Owing to these properties, neem leaf meal has been tried as a feed additive in animals.

Thus present experiment was conducted to determine the effect of dietary chitosan and neem leaf meal and their combinations at different level on fat deposition and digestive enzyme activities in broiler chickens

\section{Materials and Methods}

Two hundred and forty numbers (240) of dayold broiler chicks (Vencobb 400) were wing banded, weighed and randomly distributed to eight groups with three replicates of ten chicks each based on the body weight to namely T1,T2,T3,T4,T5,T6,T7 and T8. The experiment was undertaken in the Department of Veterinary Physiology, Veterinary College and Research Institute, Namakkal (Tamilnadu). All the chicks were reared up to 42 days in cage system under standard managemental practices with $a d$. lib. feed and water supply. The experimental diets were formulated according to the standards prescribed in Bureau of Indian Standards (BIS, 1992) and fed to the birds as per the following schedule. At the end of the experiment (42nd day), six birds per treatment group were randomly selected and slaughtered by halal method. The intestinal contents were collected in separate sterile vials for the estimation intestinal enzyme activities. The abdominal fat was collected and weighed. The eight treatment groups are as follows: 
Group T1: Basal diet without antibiotic

Group T2: Basal diet with $50 \mathrm{mg}$ Oxytetracycline $/ \mathrm{kg}$

Group T3: Basal diet without antibiotic + $0.025 \%$ chitosan

Group T4: Basal diet without antibiotic + $0.05 \%$ chitosan

Group T5: Basal diet without antibiotic + $0.5 \%$ neem leaf meal

Group T6: Basal diet without antibiotic + $1.0 \%$ neem leaf meal

Group T7: Basal diet without antibiotic + $0.025 \%$ chitosan and $0.5 \%$ neem leaf meal

Group T8: Basal diet without antibiotic + $0.05 \%$ chitosan and $1.0 \%$ neem leaf meal

\section{Estimation of amylase activity}

Estimation of amylase activity of the intestinal contents was done as per the method of Coles (1986). Briefly, one gram of intestinal contents was homogenized with 5 $\mathrm{ml}$ of distilled water, centrifuged and the supernatant was diluted to 1:1000 with 0.9 percent saline. To $1 \mathrm{ml}$ of 0.02 percent buffered starch substrate solution, $0.1 \mathrm{ml}$ of diluted supernatant was added and incubated for $9 \mathrm{~min}$ at $37^{\circ} \mathrm{C}$. In another test tube $1 \mathrm{ml}$ of 0.02 percent buffered starch substrate solution was taken as control and incubated. After incubation, one $\mathrm{ml}$ of working iodine solution was added to both the tubes. The optical density (OD) was read at $660 \mathrm{~nm}$ in a UV spectrophotometer using distilled water as blank.

Amylase activity $($ Units/ml $)=$

OD of control - OD of test

OD of control supernatant

\section{Estimation of lipase activity}

The lipase activity of the digesta was determined as per the method of Boutwell, (1962). Briefly, one gram of intestinal contents was homogenized with $10 \mathrm{ml}$ of distilled water, centrifuged and the supernatant was used for lipase estimation. Six ml of substrate buffer mixture was taken in two separate test tubes. One tube served as blank and in another tube, $5 \mathrm{ml}$ of the digesta supernatant was added, mixed thoroughly and both the tubes were incubated at $37^{\circ} \mathrm{C}$ for 24 $\mathrm{h}$. At the end of incubation, $5 \mathrm{ml}$ of the digesta supernatant was added to the blank. Then, five drops of phenolphthalein was added to the mixture and titrated against 0.05 $\mathrm{N}$ sodium hydroxide until the appearance of a distinct pink color.

Lipase activity $($ Units/g) $=$

Titre value of test - Blank value

Weight of the intestinal content $(\mathrm{g})$

\section{Statistical analysis}

The data collected were analysed using SPSS ${ }^{2} \quad 20.0$ software package. The completely randomized design method was followed for the experiment (Snedecor and Cochran, 2007) and the data collected were analysed using SPSS ${ }^{\circledR} \quad 20.0$ software package. Post-hoc analysis was done by Tukey honestly significance difference test.

\section{Results and Discussion}

The mean enzyme activities and the abdominal fat are presented in the Table 1.

\section{Amylase activity}

The mean intestinal amylase activity (U/ml) in broiler chickens were 49.15, 54.98, 55.98, $50.54,51.98,58.99$ and 59.19 in the treatment groups $\mathrm{T}_{2}$ to $\mathrm{T}_{8}$ as compared with 48.14 in the control group of broiler chickens.

Even though there was no significant difference in the mean amylase activity among any of the treatment groups and control group of broiler chickens, there was a 
numerical increase in the activity of amylase in all the treatment groups supplemented with chitosan, neem and their combination as compared with the control group of birds. Similar findings were recorded by Chen and Zhou (2005) in Silver crucian carp and Rui et al., (2013) in broiler chickens.

\section{Lipase activity}

The mean intestinal lipase activity (U/g) in broiler chickens were 41.84, 38.58, 37.27, $40.73,39.28,38.10$ and 37.11 in the treatment groups $\mathrm{T}_{2}$ to $\mathrm{T}_{8}$ as compared with 42.07 in the control group of broiler chickens.

There was no significant difference in the mean lipase activity in any of the treatment groups as compared with the control. There was a numerical decrease in the lipase activity in the chitosan supplemented groups $\left(\mathrm{T}_{3}, \mathrm{~T}_{4}\right.$, $\mathrm{T}_{7}$ and $\mathrm{T}_{8}$ ) and these groups recorded lower lipase activity.

The results of the present study agree with the findings of $\mathrm{Xu}$ et al., (2014) who observed that the lipase activity of proximal jejunum contents was not affected by increasing chitosan supplementation from $0-500 \mathrm{mg} / \mathrm{kg}$ in weaned piglets on days 14 and 28 . The results of the present study differs with those of Kobayashi et al., (2002) who observed dietary chitosan $(50 \mathrm{gm} / \mathrm{kg})$ in broiler chicken diet significantly $(\mathrm{p}<0.01)$ decreased lipase activity per gm of small intestinal contents. The lipase activity in the treatment groups did not show any significant variation as the dose of chitosan $(0.025-0.05 \%)$ supplemented in the present study was comparatively lesser.

Bile salts are essential for emulsification of dietary fat and activation of pancreatic lipase activity. Dietary chitosan binds with the bile salts and decreases bile acid concentration in the duodenum of chickens (Razdan and Pettersson, 1994) which might have lowered the intestinal lipase activity.
Hence, it could be inferred that the supplementation of antibiotic, chitosan, NLM and chitosan NLM combination had no influence on the activities of intestinal amylase and lipase except that the chitosan supplemented groups recorded lower lipase activity.

\section{Abdominal Fat}

The mean abdominal fat $(\%)$ in broiler chickens were $1.85,1.39,1.29,1.82,1.84$, 1.37 and 1.26 in the treatment groups $\mathrm{T}_{2}$ to $\mathrm{T}_{8}$ as compared with 2.03 in the control group of broiler chickens.

The mean abdominal fat (\%) was significantly $(\mathrm{p}<0.05)$ higher in the control group, $\mathrm{T}_{2}, \mathrm{~T}_{5}$ and $\mathrm{T}_{6}$ groups of broiler chickens as compared with the treatment groups $\mathrm{T}_{3}, \mathrm{~T}_{4}, \mathrm{~T}_{7}$ and $\mathrm{T}_{8}$.

There was no significant difference in the mean abdominal fat in the NLM supplemented group and control birds. These findings concur with those of Landy et al., (2011) who reported that the neem fruit powder supplementation at 7 or $12 \mathrm{~g} / \mathrm{kg}$ diet had no significant influence on the abdominal fat percentage in broilers. Similar observations were made by Bonsu et al., (2012) who found that fat isolated from the lower abdomen was significantly $(\mathrm{P}<0.05)$ higher in the control birds when compared with that of birds fed the NLM at 2 per cent but did not differ significantly $(\mathrm{P}>0.05)$ from the NLM at 1.5 and 2.5 per cent. Dietary chitosan inhibits the micelle formation during the lipid digestion in the digestive tract by forming ionic bond with the bile salts and acids, lipids and fatty acids directly thereby decreases the body fat deposition by reducing intestinal fat absorption and hepatic triglyceride synthesis and increasing the fecal lipid excretion (Zhou et al., 2006). 
Table.1 Mean ( \pm S.E.) Intestinal digestive enzymes and abdominal fat of broiler chickens

\begin{tabular}{|l|c|c|c|}
\hline \multicolumn{1}{|c|}{ Treatment groups } & $\begin{array}{c}\text { Amylase activity } \\
(\mathbf{U} / \mathbf{m l})\end{array}$ & $\begin{array}{c}\text { Lipase activity } \\
(\mathbf{U} / \mathbf{g})\end{array}$ & $\begin{array}{c}\text { Abdominal fat } \\
(\%)\end{array}$ \\
\hline $\begin{array}{l}\mathrm{T}_{1}-\text { Basal diet } \\
\text { (without antibiotic) }\end{array}$ & $48.14 \pm 1.56$ & $42.07 \pm 0.35$ & $2.03^{\mathrm{b}} \pm 0.23$ \\
\hline $\begin{array}{l}\mathrm{T}_{2}-\text { Basal diet + 50 mg } \\
\text { Oxytetracycline/kg }\end{array}$ & $49.15 \pm 1.84$ & $41.84 \pm 0.35$ & $1.85^{\mathrm{b}} \pm 0.24$ \\
\hline $\begin{array}{l}\mathrm{T}_{3}-\text { Basal diet + 0.025\% } \\
\text { chitosan }\end{array}$ & $54.98 \pm 1.67$ & $38.58 \pm 0.64$ & $1.39^{\mathrm{a}} \pm 0.16$ \\
\hline $\begin{array}{l}\mathrm{T}_{4}-\text { Basal diet + 0.05\% } \\
\text { chitosan }\end{array}$ & $55.98 \pm 1.46$ & $37.27 \pm 0.43$ & $1.29^{\mathrm{a}} \pm 0.20$ \\
\hline $\begin{array}{l}\mathrm{T}_{5}-\text { Basal diet + 0.5\% } \\
\text { NLM }\end{array}$ & $50.54 \pm 1.56$ & $40.73 \pm 0.17$ & $1.82^{\mathrm{b}} \pm 0.14$ \\
\hline $\begin{array}{l}\mathrm{T}_{6}-\text { Basal diet + 1.0\% } \\
\text { NLM }\end{array}$ & $51.98 \pm 1.58$ & $39.28 \pm 0.27$ & $1.84^{\mathrm{b}} \pm 0.11$ \\
\hline $\begin{array}{l}\mathrm{T}_{7}-\text { Basal diet 0.025\% } \\
\text { chitosan +0.5\% NLM }\end{array}$ & $58.99 \pm 1.65$ & $38.10 \pm 0.38$ & $1.37^{\mathrm{a}} \pm 0.21$ \\
\hline $\begin{array}{l}\mathrm{T}_{8}-\text { Basal diet + 0.05\% } \\
\text { chitosan +1.0\% NLM }\end{array}$ & $59.19 \pm 1.46$ & $37.11 \pm 0.20$ & $1.26^{\mathrm{a}} \pm 0.19$ \\
\hline
\end{tabular}

Means within the same column bearing different superscripts differ significantly $(\mathrm{p}<0.05)$

Chitosan can therefore reduce the ectopic accumulation of lipids (triglycerides) both in the liver and muscle tissue. Chitosan counteracts triglyceride accumulation in the liver (decrease of triglyceride content by $39 \%$ ) and in the muscle (decrease of triglyceride content by 66\%) (Neyrinck et al., 2009).

Supplementation of chitosan alone or in combination with NLM at both levels resulted in significant reduction in abdominal fat in comparison to all other treatment and control groups.

In conclusion, modern broiler strains have excessive abdominal fat deposit, has a negative impact on poultry production, as evidenced by the increase in feed cost during rearing, decrease in the final meat quality, and the significant economic loss to poultryprocessing plants. Due to the economic concerns and consumer aversion to excess fat deposition, excess fat control and improvement of meat quality are among the targets of broilers production. Chitosan, an abundantly available biopolymer in combination with neem leaf meal can be supplemented in the diet of broiler chickens to reduce the abdominal fat without having any adverse effect on the intestinal enzyme activities.

\section{Acknowledgement}

The authors acknowledge the Dean, Veterinary College and Research Institute, Namakkal and Tamilnadu Veterinary and Animal Sciences University for providing research facilities for the present study.

\section{References}

Austine, P.R., Brine, C.J., Castle, J.E. and Zikakis, J.P. 1981. Chitin: new facets of research. Sci., 212: 749-753. 
Brahmachari, G. 2004. Neem - an omnipotent plant, Chem. Biochem. 5: 408-421.

BIS. 1992. Nutrient requirements for poultry. Bureau of Indian Standards, I.S.13574.

Boutwell, Jr. J.A. 1962. Clinical Chemistry Laboratory Manual Methods. $1^{\text {st }}$ Edn., Lea and Febiger, Philadelphia. pp. 212214.

Bonsu, F.R.K., Kagya-Agyemang, J.K., Kwenin, W.K.J. and Zanu, H.K. 2012. Medicinal response of broiler chickens to diets containing neem (Azadirachta indica) leaf meal, haematology and meat sensory analysis. World App. Sci. J., 19: 800-805.

Chen, Y. and Zhou, H.Q. 2005. Effect of three kinds of polysaccharide on protease activity amylase activity in intestine and hepatopancreas of allogynogenetic silver crucian carp. $J$. Shanghai Fish. Univ., 14: 468-471.

Coles, E.H. 1986. Veterinary Clinical Pathology. $4^{\text {th }}$ Edn., W.B. Saunders Company, Philadelphia. pp. 420-421.

Gopalakannan, A. and Venkatesan, A. 2006. Immunomodulatory effect of dietary intake of chitin, chitosan and levamisole on the immune system of Cyprinus carpio and control of Aeromonas hydrophila infection in ponds. Aquaculture, 255: 179-187.

Kobayashi, S., Terashima, Y. and Itoh, H. 2002. Effects of dietary chitosan on fat deposition and lipase activity in digesta in broiler chickens. Br. Poult. Sci., 43: 270-273.

Koul, A., Ghara, A.R. and Gangar, S.C. 2006. Chemomodulatory effects of Azadirachta indica on the hepatic status of skin tumor bearing mice. Phytother. Res., 20: 169-177.

Landy, N., Ghalamkari, G. and Toghyani, M. 2011. Performance, carcass characteristics, and immunity in broiler chickens fed dietary neem (Azadirachta indica) as alternative for an antibiotic growth promoter. Livest. Sci., 142: 305-309.

Nasir, Z., Grashorn, M.A. 2006. Use of Black cumin (Nigella sativa) as alternative to antibiotics in poultry diets. 9th Tagung Schweine-und Geflügelernährung, Halle (Saale), Germany, pp. 210-213.

Neyrinck, A.M., Bindels, L.B., Backer, F.D., Pachikian, B.D., Cani, P.D. and Delzenne, N.M. 2009. Dietary supplementation with chitosan derived from mushrooms changes cytokine profile in diet-induced obese mice, a phenomenon linked to its lipid-lowering action. Int. Immunopharmacol., 9: 767773.

Rajendran, R., Radhai, R., Balakumar, C., Mohammad Ahmaed, H.A., Vigneshwaran, C. and Veideki, K. 2012. Synthesis and characterization of neem chitosan nanocomposites for development of antimicrobial cotton textiles. J. Eng. Fiber Fabr., 7: 136141.

Razdan, A. and Pettersson, D. 1994. Effect of chitin and chitosan on nutrient digestibility and plasma lipid concentrations in broiler chickens. $B r$. J. Nutr., 72: 277-288.

Razdan, A. and Pettersson, D. 1996. Hypolipidaemic, gastrointestinal and related responses of broiler chickens to chitosans of different viscosity. $B r . J$. Nutr., 76: 387-397.

Razdan, A., Pettersson, D. and Pettersson, J. 1997. Broiler chicken body weight, feed intakes, plasma lipid and small intestinal bile acid concentrations in response to feeding of chitosan and pectin. Br. J. Nutr., 78: 283-291.

Rui, G.R., Rui-Jin, L. and Lan, W. 2013. Effect of dietary supplementation with low molecular weight chitosan on growth and digestive enzyme activities in common carp (Cyprinus carpio). $J$. 
Food Sci., 34: 8-12.

Shahidi, F., Kamil, J., Arachchi, V. and Jeon, Y.J. 1999. Food applications of chitin and chitosans. Trends Food Sci. Technol., 10: 37-51.

Snedecor, G.M. and Cochran, W.C. 2007. Statistical Methods. 8th Edn. Oxford and IBH Publishing Company,Mumbai, India.

Tin, S., Sakharkar, K.S., Lim, C.S. and Sakharkar, M K. 2009. Activity of chitosans in combination with antibiotics in Pseudomonas eruginosa. Int. J. Biol. Sci., 5: 153-160.

Tiwari, R., Verma, AK., Chakraborty, S., Dhama, K. and Singh, S.V. 2014. Neem (Azadirachta indica) and its potential for safegurding health of animal and humans: A review. J. Bio. Sci., 14:
$110-123$.

Xu, Y., Shi, B., Yan, S., Li, J., Li, T., Guo, Y. and Guo, X. 2014. Effects of chitosan supplementation on the growth performance, nutrient digestibility, and digestive enzyme activity in weaned pigs. Czech. J. Anim. Sci., 59: $156-163$.

Yin, H., Du, Y. and Zhang, J. 2009. Low molecular weight and oligomeric chitosans and their bioactivities. Curr. Top. Med. Chem., 9: 1546-1559.

Zhou, K., Xia, W., Zhang, C. and Yu, L. 2006. In vitro binding of bile acids and triglycerides by selected chitosan preparations and their physicochemical properties. Food Sci. Technol., 39: 1087-1092.

\section{How to cite this article:}

Sirsat Shraddha, D., P. Visha and Nanjappan, K. 2017. Effects of Dietary Chitosan and Neem Leaf Meal Supplementation on Digestive Enzyme Activities and Fat Deposition in Broiler Chickens. Int.J.Curr.Microbiol.App.Sci. 6(5): 469-475. doi: https://doi.org/10.20546/ijcmas.2017.605.054 